\title{
ANÁLISE DAS PAISAGENS DO LITORAL SUL DO ESTADO DE SÃO PAULO
}

\section{Analysis of landscapes of the South Coast in São Paulo State (Brazil)}

\author{
Renê Lepiani Dias \\ Doutorando em Geografia, Departamento de Geografia, Instituto de Geociências, \\ Universidade Estadual de Campinas - UNICAMP \\ renelepiani@ige.unicamp.br \\ Regina Célia de Oliveira \\ Profa. Dra. do Departamento de Geografia, Instituto de Geociências, \\ Universidade Estadual de Campinas - UNICAMP \\ reginacoliveira@ige.unicamp.br
}

Artigo recebido em 16/11/2011 e aceito para publicação em 02/07/2012

RESUMO: O Litoral Sul do Estado de São Paulo estrutura-se sob dois grandes domínios morfoestruturais: Cinturão Orogênico do Atlântico e Bacias Sedimentares Cenozóicas. Nesta área são encontradas morfologias diversas, que se apresentam na forma de escarpas com caimentos topográficos abruptos, vales entalhados em uma importante rede fluvial, topos aguçados a convexos sob domínio da Mata Atlântica, e extensa planície com presença de depósitos inconsolidados e importantes sistemas ambientais, como os manguezais. A paisagem em que se organiza a área de estudo revela sistemas com fragilidades complexas e que sofrem há séculos pressões de uso, resultando em cenários catastróficos, seja pela ocorrência de processos vinculados a movimentos de massa ou inundações, com perdas materiais e humanas. O objetivo deste trabalho foi a delimitação de geossistemas, como unidades naturais, a partir da análise das paisagens, tendo em vista o uso e ocupação das terras.

Palavras-chaves: Paisagem, Geossistema, Uso e Ocupação da Terra, Geomorfologia

ABSTRACT: The South Coast of São Paulo is structured in two main areas morphostructural: Atlantic Orogenic Belt and Cenozoic Sedimentary Basins. In this area are found various morphologies, that are in the form of trims topographic scarps, valleys carved, organization of major river network, the sharp convex tops in the Atlantic Forest domain extensive plain with the presence of unconsolidated deposits and important environmental systems, such as those related to mangroves. The landscape in which organizes itself in the study area reveals weaknesses in complex systems and suffering from centuries of use pressures, resulting in doomsday scenarios, either by the occurrence of processes related to mass movements or floods, with material and human losses. The objective of this study was the delimitation of geosystems, as natural units, from the analysis of landscapes, in view of the use and occupation of land.

Keywords: Landscape, Geosystem, Land Use and Occupancy, Geomorphology 


\section{INTRODUÇÃO}

As regiões litorâneas constituem sistemas ambientais de grande fragilidade e vulnerabilidade devido aos processos e características predominantes, sendo áreas instáveis naturalmente. A interação entre o ambiente terrestre e marinho permite a presença de elementos naturais únicos, como manguezais, praias, dunas, estuários, entre outros.

A ação antrópica em áreas costeiras, desde longa data, corresponde a níveis diversos de intervenção no funcionamento dos sistemas ambientais, que resulta em impactos consideráveis. Desde as primeiras civilizações, a proximidade com os mares atraiu as populações devido à disponibilidade dos recursos continentais e marinhos, além de proporcionar trocas comerciais com outros povos. Desta forma, essas áreas sempre foram transformadas pelo homem, apresentando diversos problemas em seu uso e ocupação.

Segundo Amorim e Oliveira (2007), exemplos de danos causados nos ambientes costeiros são identificados em todo o território brasileiro, entre os quais se destacam o desmatamento dos biomas, aterro dos manguezais, lançamento de efluentes domésticos e industriais nos cursos de água, e construções nas zonas de praias que alteram a dinâmica da deriva dos sedimentos, resultando em diversos níveis de impactos aos sistemas ambientais.

Com o desenvolvimento de pesquisas aplicadas às zonas costeiras, há a necessidade de estudar áreas de grande complexidade natural e com processo de uso e ocupação antrópica, que modificaram os geossistemas, como é o caso do Litoral Sul do Estado de São Paulo.

Os geossistemas, objeto de estudo da Geografia Física, segundo a concepção metodológica de Sotchava (1977 e 1978), têm sido utilizados para subsidiar propostas de uso e ocupação das terras.

Segundo Sotchava (1977), os geossistemas são definidos como fenômenos naturais (aspectos geomorfológicos, climáticos, hidrológicos e fitogeográficos) influenciados pelos fenômenos antrópicos (aspectos sociais, culturais e econômicos). Juntos representam a paisagem modificada ou não pela sociedade. O conceito de paisagem é a principal categoria de análise no estudo dos geossistemas.
Bertrand (1971) define a paisagem como certa porção do espaço, resultante da interação dinâmica e instável dos atributos físicos, biológicos e antrópicos, que reagindo dialeticamente uns sobre os outros, fazem dela um conjunto único e indissociável.

Para Guerra e Marçal (2006), o estudo sobre geossistemas requer reconhecimento e análise dos componentes naturais, principalmente de suas conexões. Os geossistemas, como unidades naturais, se distinguem por suas modificações e transformações resultantes das ações dos diferentes tipos de uso e ocupação das terras.

Independente do nível técnico alcançado pelos estudos geomorfológicos litorâneos e de sua contribuição para o equacionamento dos problemas ambientais, estes assumiram caráter emergencial nas áreas em processo de urbanização.

Esses problemas ambientais foram identificados no Litoral Sul do Estado de São Paulo, mais especificamente nos municípios localizados na zona de influência costeira, como é o caso de Iguape, Ilha Comprida e Cananéia, cujos sistemas naturais apresentam grande complexidade advinda dos fatores estruturais que regem a dinâmica de esculturação da paisagem. $\mathrm{Na}$ área de estudo observa-se a ocorrência de dois importantes domínios morfoestruturais: o Cinturão Orogênico do Atlântico e as Bacias Sedimentares Cenozóicas (ROSS e MOROZ, 1997).

Deste modo, este trabalho justifica-se pela importância de estudos de natureza ambiental, que possam apontar as fragilidades dos geossistemas frente à necessidade de uso e ocupação das terras, que correspondem à dinâmica de funcionamento da paisagem. Contribuindo para planos de disciplinamento e planejamento, que venham intervir com menor risco possível à qualidade dos sistemas ambientais.

\section{LOCALIZAÇÃO E CARACTERIZAÇÃO FÍSI- CA DA ÁREA DE ESTUDO}

Os municípios que ocupam a área do Litoral Sul do Estado de São Paulo apresentam mais de 50.000 habitantes de acordo com dados do censo do IBGE (2010). Geograficamente, estão localizados entre as coordenadas de $24^{\circ} 42^{\prime} \mathrm{S}$ e $25^{\circ} 00^{\prime} \mathrm{S}$ de latitudes e entre as coordenadas de $47^{\circ} 33^{\prime}$ 'W e $47^{\circ} 55^{\prime} \mathrm{W}$ de longitude, distante aproximadamente $210 \mathrm{~km}$ da capital paulista (Figura 1). 
Figura 1: Localização Geográfica da área de estudo

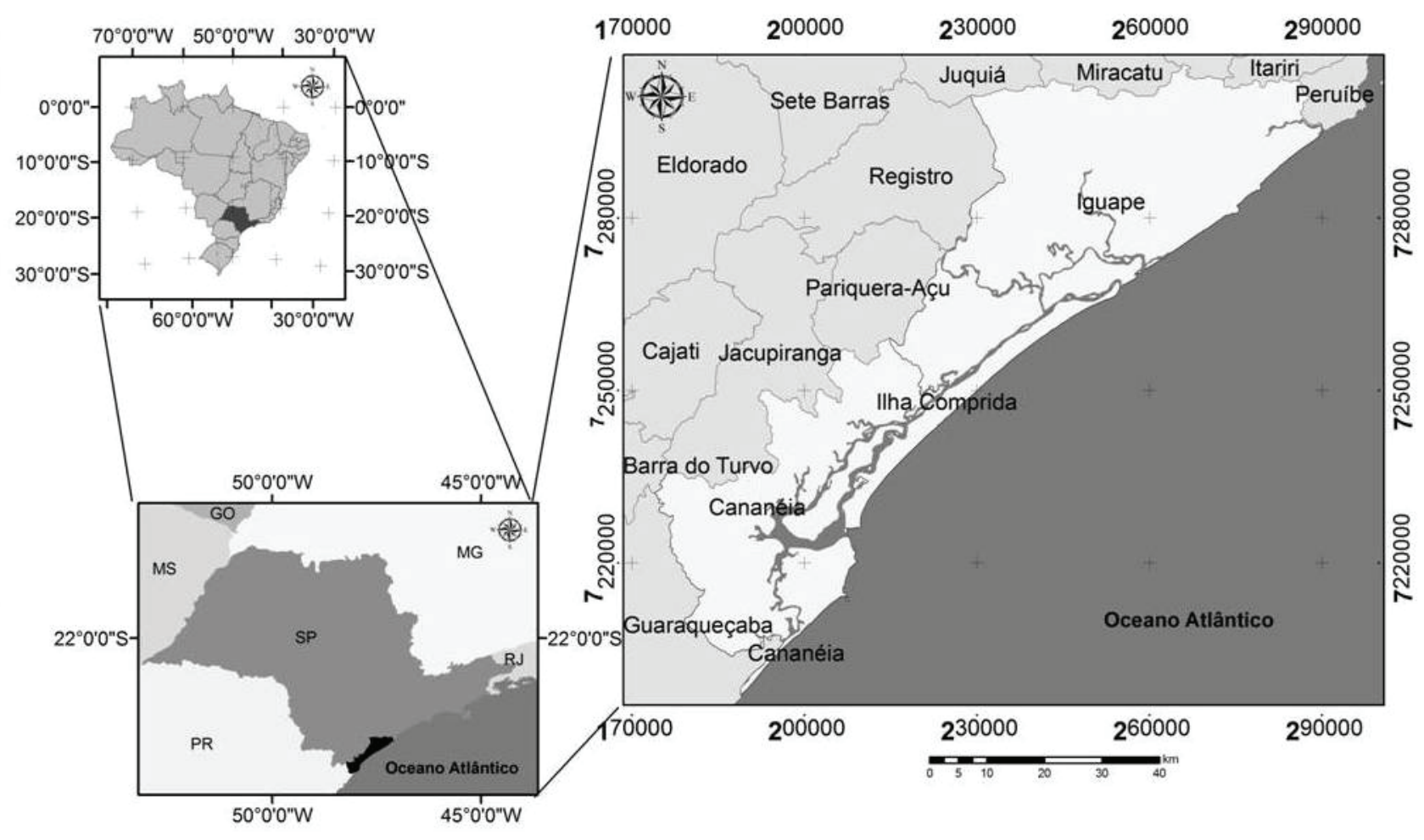

Fonte: IBGE, 2000 (Adaptado)

O clima reinante é subtropical úmido, com temperatura média anual em torno $\operatorname{dos} 28^{\circ} \mathrm{C}$, apresenta quatro estações bem definidas, com invernos frios (temperaturas ao redor de $13^{\circ} \mathrm{C}$ ) e verões quentes (temperaturas ao redor de $29^{\circ} \mathrm{C}$ ), com pluviosidade média anual entre 1700 a $1800 \mathrm{~mm}$.

Para compreensão da dinâmica da paisagem do Litoral Sul do Estado de São Paulo deve-se considerar a análise sistêmica dos processos morfogenéticos, delimitando os compartimentos geomorfológicos através de dois parâmetros de diferenciação. O primeiro representado pelos condicionantes geológicos e geomorfológicos; e o segundo representado pelos condicionantes climáticos e oceanográficos.

A área de estudo foi subdividida em dois domínios geológicos e geomorfológicos. O Cinturão Orogênico do Atlântico (ROSS e MOROZ, 1997), ou Serrania Costeira (ALMEIDA, 1964), constituído por rochas do embasamento cristalino, com idades Pré-Cambrianas a Paleozóicas, porém com algumas manifestações ígneas Mesozóicas, no qual prevalecem processos erosivos e transporte de material erodido. As
Bacias Sedimentares Cenozóicas (ROSS e MOROZ, 1997) ou definidas por IPT (1981) como Baixadas Litorâneas, constituídas por depósitos sedimentares Cenozóicos, nos quais prevalece a deposição e o retrabalhamento marinho de materiais.

A zona denominada Serrania Costeira caracteriza-se, geomorfologicamente, pela presença de escarpas abruptas, intercaladas em anfiteatros sucessivos, separados por espigões. Para o IPT (1981), a subzona Serra do Mar é descaracterizada a partir da região de Peruíbe para SW, pela expansão da bacia hidrográfica do Ribeira de Iguape, que forma regiões serranas complexas. Os relevos limítrofes do Planalto Atlântico, voltados para o mar, reaparecem nos confins do Estado de São Paulo, na região a noroeste da Ilha do Cardoso.

A subzona Serrania de Itatins, que segundo o IPT (1981), constitui-se em uma área alongada de direção E-W, extremamente acidentada, com altitudes desde alguns metros até valores superiores a 1100 metros. A região é constituída por migmatitos e granulitos, separada das áreas pré-cambrianas a norte e a 
nordeste pelas falhas transcorrentes de Itariri e Cubatão. A subzona Serrania do Ribeira é caracterizada pelo autor op. cit. por um forte entalhamento, a partir de áreas niveladas a 900-1100 metros, com grandes amplitudes de relevo. Nos confins do Estado de São Paulo, a Serrania do Ribeira cede lugar novamente à subzona da Serra do Mar.

Outro compartimento presente são os Morros Residuais, mostrando que no passado o Planalto Atlântico possuía uma área maior que a atual (IPT, 1981).

Para Almeida (1964), as Baixadas Litorâneas Paulistas compreendem áreas restritas de planícies mais ou menos isoladas, ou seja, dispostas em áreas descontínuas à beira-mar, não ultrapassando 70 metros de altitude.

As Baixadas Litorâneas desenvolvem-se sobre um pacote de sedimentos quaternários de espessura variada, que obedecem ao mesmo padrão de distribuição em toda a costa paulista (IPT, 1981).

Verifica-se a presença de terraços marinhos, que segundo Guerra (1993), constituem uma superfície horizontal ou suavemente inclinada formada pela deposição de sedimentos, ou uma superfície topográfica modelada pela erosão marinha, limitada por declives de mesmo sentido.

Ocorre a formação de planícies flúvio-marinhas, que são terrenos baixos, sujeitos às inundações das marés. Esses terrenos são constituídos por lamas de depósitos recentes. Verifica-se também a presença de planície marinha, formada pela deposição de sedimentos devido à ação do mar, através das correntes de deriva litorânea, das marés e das ondas. Os sedimentos são constituídos, em sua grande maioria, por areias finas inconsolidadas (HENRIQUE, 2001).

Dessa forma, as áreas litorâneas possuem potencial de fragilidade muito alto por serem sujeitas a inundações periódicas, devido ao lençol freático pouco profundo e aos sedimentos inconsolidados, que sofrem acomodações constantes.

Os geossistemas do Litoral Sul do Estado de São Paulo são caracterizados de acordo com seus aspectos naturais, referentes à sua função nos fluxos e armazenamento de matéria e energia, como produto da interação de diversos fatores, como os aspectos geológicos, climáticos, pedológicos, geomorfológicos, fluviais, bióticos e oceanográficos. É importante ressaltar que a interação e a ação de cada um desses fatores variam para cada geossistema definido.

As áreas emissoras (topos), transmissoras (vertentes), receptoras (planícies) e transmissoras/ receptoras (mangues e praias) representam os geossistemas, identificados na área de estudo.

Conhecer os mecanismos responsáveis pela configuração dos geossistemas na zona costeira é importante para o planejamento em áreas litorâneas. A intervenção antrópica, sem a devida atenção aos processos morfodinâmicos, oceânicos ou continentais, pode ocasionar problemas ambientais muitas vezes irreversíveis na faixa costeira.

\section{MÉTODOS E TÉCNICAS}

A base teórica deste trabalho está fundamentada na proposta metodológica de Rodriguez (1994) e Rodriguez, Silva e Cavalcanti (2004) sobre análise geossistêmica, que tem como objeto de estudo os geossistemas, baseados na relação dos componentes naturais e antrópicos, a partir da caracterização sócio-econômica e geoecológica da paisagem.

A paisagem, a partir da análise geossistêmica, é entendida como um sistema aberto, ou seja, apresenta relação constante com outros sistemas circundantes através da troca de matéria e energia (RODRIGUEZ, 1994).

Segundo Rodriguez (1994), a paisagem é compreendida a partir da composição e inter-relação dos geocomponentes, como natureza, economia, sociedade e cultura, relacionando os elementos naturais com os antrópicos.

A partir da visão sistêmica, concebe-se a paisagem como um sistema integrado, no qual cada componente isolado não possui propriedades integradoras. Estas propriedades somente desenvolvem-se quando se estuda a paisagem como um todo, e o todo não é o resultado da soma das partes, depende da intensidade das interações e inter-relações que ocorrem entre as partes (RODRIGUEZ, SILVA e CAVALCANTI, 2004).

Além disto, de acordo com os autores op. cit. a concepção dialética, sobre a interação entre as condições naturais e a produção social, determina os princípios metodológicos da investigação da paisagem. 
Segundo Rodriguez, Silva e Cavalcanti (2004), a regionalização e a tipologia são fatores fundamentais na análise da paisagem, constituindo a base das propriedades espaços-temporais dos complexos territoriais que se reproduzem pela influência dos fatores naturais e antropogênicos.

Cinco enfoques são abrangidos na análise da paisagem, que tratam fundamentalmente das idéias, conceitos e métodos de estudo: (a) estrutural; (b) funcional; (c) evolutivo-dinâmico; (d) antropogênico e integrativo da estabilidade; e (e) sustentabilidade da paisagem. Estes enfoques têm como função, a procura de subsídios para o desenvolvimento do território (RODRIGUEZ, SILVA e CAVALCANTI, 2004).

Para a realização deste trabalho adotou-se o enfoque funcional para analisar as propriedades integradoras da paisagem como um sistema total, com a finalidade de esclarecer a estruturação e as relações funcionais (naturais e sociais) de seus elementos. Segundo este enfoque todos os elementos da paisagem cumprem funções determinadas e participam de forma peculiar no processo de gênese.

Tal enfoque considera que é necessário estudar o objeto de forma direta, determinando as relações estruturadas entre seus elementos, fixado de forma histórica sobre a base de determinadas propriedades genéticas da paisagem. A ação conjunta dos fatores, componentes e processos no tempo é um fator determinante na formação e funcionamento da paisagem.

Define-se como funcionamento da paisagem a seqüência estável de processos que atuam permanentemente e que consistem na transmissão de energia, substâncias e informações, garantindo a conservação de um estado da paisagem, característico para um tempo dado (DIAKONOV, 1988 apud RODRIGUEZ, SILVA e CAVALCANTI, 2004).

Os geossistemas são considerados formações naturais (SOTCHAVA, 1977), que obedecem à dinâmica dos fluxos de matéria e energia, inerentes aos sistemas abertos, conjuntamente com os inputs, formando um modelo global de apreensão da paisagem. $\mathrm{O}$ homem, enquanto ser social, interfere no meio natural, por meio do uso e ocupação das terras, proporcionando a modificação da paisagem.

Embora os geossistemas sejam fenômenos naturais, todos os fatores econômicos e sociais, in- fluenciando sua estrutura e peculiaridades espaciais, são tomados em consideração durante seu estudo e suas descrições. As ditas paisagens antropogênicas nada mais são do que estados variáveis de primitivos geossistemas, podendo ser referidos à esfera de estudo do problema da dinâmica da paisagem (SOTCHAVA, 1978).

Pode-se definir a função geoecológica do geossistema como objetivo que cumpre o sistema em garantir a estrutura e funcionamento, tanto do próprio geossistema, como do sistema superior ao qual pertence. Definem-se de maneira qualitativa, as funções geoecológicas, agrupadas em três grandes classes (RODRIGUEZ, 1994):

- Áreas Emissoras: são os níveis mais elevados do terreno (topos), com maior tendência a serem "lavadas" pelas chuvas, garantindo o fluxo de matéria e energia para o restante da área;

- Áreas Transmissoras: são aquelas em que predomina o transporte dos fluxos de matéria e energia das áreas mais elevadas para as áreas mais baixas, como por exemplo, as encostas, representadas pelas vertentes e patamares;

- Áreas de Acumulação: são locais onde ocorre a coleta da matéria e energia provenientes das áreas mais elevadas e, a partir daí, são novamente transmitidas de forma concentrada ou seletivamente através dos canais fluviais. Segundo Rodriguez (1994), se insere no contexto de paisagens dinâmicas recentes ou em estado evolutivo. São exemplos deste ambiente, os fundos de vale e as planícies.

O enfoque funcional da paisagem propõe estudos referentes à dinâmica e aos processos geoecológicos degradantes. Segundo Diakonov (1988) apud Rodriguez, Silva e Cavalcanti (2004), o conjunto dos processos que garante o funcionamento dos geossistemas é aquele que se define como dinâmica funcional. Cada paisagem tem sua própria dinâmica funcional, que é sustentada por mecanismos e balanços de fluxos de energia, matéria e informação específicas e por uma cadeia de relações reversíveis que asseguram a integridade do sistema. 
A função geoecológica é a perda de atributos e propriedades do sistema que garantem as funções e os mecanismos de auto-regulação. Assim a degradação tem papel contrário à atividade dos processos geoecológicos (vinculados ao funcionamento da paisagem), e conduzem à mudança nos mecanismos de auto-regulação, circulação de fluxos de energia, matéria $\mathrm{e}$, por conseguinte, à perda dos potenciais naturais e da capacidade produtora dos sistemas (RODRIGUEZ, SILVA e CAVALCANTI, 2004).

Os processos geoecológicos degradantes resultam da ação antrópica sobre a paisagem ou do esforço dos processos naturais. Dentre os processos geoecológicos destacam-se aqueles de interação (formados pela influência decisiva da ação antrópica), como por exemplo, a contaminação (do solo, da atmosfera e da água), a alteração dos recursos hídricos, a perda da biodiversidade e a degradação do solo.

As alterações dos mecanismos de formação e regulação sistêmica, o grau e amplitude dos processos degradantes, e o nível de degradação, determinam o estado ambiental do geossistema, considerando o tipo, o grau de impacto e a capacidade de reação e absorção. Rodriguez e Martinez (1998) apud Rodriguez, Silva e Cavalcanti (2004) apresentam uma classificação de cinco níveis para determinar o estado ambiental dos geossistemas.

- Estável (não alterado): conserva-se a estrutura original. Não existem problemas ambientais significativos que deteriorem a paisagem. O nível dos processos geoecológicos tem um caráternatural. A influência antropogênica é muito pequena. São núcleos de estabilidade ecológica, principalmente paisagens primárias ou paisagens naturais com limitado uso antropogênico;

- Medianamente estável (sustentável): refletem poucas mudanças na estrutura. Incidem alguns problemas de intensidade leve a moderada, que não alteram o potencial natural e a integridade do geossistema. Constituem áreas que são desenvolvidas e utilizadas pelo homem, de tal forma, que o uso e ocupação das terras estão balanceados com o potencial e podem ser sustentados por várias gerações. Estas áreas necessitam de manutenção de baixo custo e cuidado para assegurar que continue a sustentabilidade;

- Instável (insustentável): fortes mudanças da estrutura espacial e funcional, de tal maneira que não consegue cumprir as funções ecológicas. A incidência de alguns problemas ambientais resultantes da exploração dos recursos dá lugar a um declínio na produtividade, que provavelmente se perca no curso de uma geração;

- Crítico: perda parcial da estrutura espacial e funcional com eliminação paulatina das funções ecológicas. Manifesta um número significativo de problemas ambientais de forte intensidade. Áreas, nas quais o uso da terra e o impacto humano excederam a capacidade de suporte dos geossistemas. Resulta em uma drástica redução do potencial da terra. As paisagens que estão neste estado necessitam da aplicação de medidas de mitigação urgentes e imediatas para recuperar o potencial natural. A mitigação dos processos geoecológicos levará pelo menos uma geração;

- Muito crítico: perda e alteração generalizada da estrutura espacial e funcional. O geossistema não está em condições de cumprir suas funções geoecológicas. Experimentam a atividade de um número significativo de problemas ambientais de intensidade muito forte. O potencial inicial dos recursos foi completamente destruído. Não são áreas adequadas para o uso humano. A população necessita ser realocada, que implica enormes custos.

Considerando as proposições apresentadas pela metodologia adotada neste trabalho (RODRIGUEZ, 1994 e RODRIGUEZ, SILVA e CAVALCANTI, 2004), foi possível, a partir da integração dos componentes naturais, da dinâmica de uso e ocupação das terras, trabalho de campo e levantamento bibliográfico, elaborar a documentação cartográfica, representada pelas cartas: Carta de Geossistemas, Carta de Sistemas Antropo-Naturais e Carta de Estado Ambiental.

A Carta de Geossistemas foi elaborada a partir da análise dos componentes naturais (geologia, 
geomorfologia, clima, formação superficial, pedologia, compartimentos geomorfológicos) e tem como principal enfoque discutir a demarcação das unidades na dinâmica de fluxo de matéria e energia entre os sistemas, definindo-se quatro sistemas:

- Zonas Dispersoras: relacionadas às áreas de topos da região serrana, prevalecem dispersão e movimentação do material erodido, com alto índice de energia potencial.

- Zonas Transmissoras: relacionadas às áreas de escarpas que apresentam alto grau de declive, caracterizam-se por alta energia cinética em comparação às zonas de dispersão, que resultam em alto fluxo de material neste sistema. Prioriza a mobilização do material que foi erodido.

- Zonas Receptoras/Acumuladoras: relacionadas às áreas de planícies, se distinguem pelo baixo fluxo de energia, por apresentarem baixo declive e possuírem grande extensão territorial. Tem como característica principal a dissipação da energia cinética das zonas transmissoras. Neste sistema prevalece a deposição do material erodido das outras unidades.

- Zonas Transmissoras e Receptoras/ Acumuladoras: relacionadas às áreas de contato entre continente/oceano, têm como principal característica o baixo declive, que permite a deposição de material, tendo seus limites na área de oscilação das marés. Devido ao contato entre continente e oceano, há um alto fluxo de energia cinética dentro destes sistemas, que propicia a erosão do material depositado e seu retrabalhamento, além de grande parte ser transportado pelas marés até a plataforma continental.

Com a identificação dos geossistemas a partir da dinâmica de fluxo de energia e matéria, foi realizada a subdivisão pelas características morfológicas apresentadas, com o intuito de identificar os processos morfogenéticos atuantes em cada um.

A Carta de Sistemas Antropo-Naturais foi elaborada a partir da correlação dos dados adquiridos no levantamento sócio-econômico e histórico. Foram identificados dois grupos baseados no uso e ocupação das terras.

- Sistemas Antrópicos:

- Sistemas Urbanos;

- Sistemas Rurais e Usos Associados;

- Sistemas Agrícolas Permanentes.

- Sistemas Naturais:

- Sistemas de Formação Florestal;

- Sistema de Cobertura Vegetal Costeira;

- Sistema de Depósito Costeiro.

Com a identificação dos sistemas antropo-naturais, a partir do uso e funcionalidade de cada sistema, foram realizados a subdivisão com o intuito de identificar os processos de ocupação e funcionalidade presentes nos sistemas identificados.

A Carta de Estado Ambiental foi elaborada a partir da correlação dos sistemas antrópicos e dos geossistemas, a fim de analisar e produzir uma avaliação qualitativa das potencialidades, do estado e da utilização dos sistemas ambientais, a partir de parâmetros físicos. Analisou-se a estabilidade de cada geossistema, utilizando sua dinâmica de processos morfogenéticos e seu nível de instabilidade, isto é, a capacidade de auto-regeneração, o impacto do tipo de uso relacionado e os problemas ambientais levantados nestas áreas.

Esta carta apresenta as classes qualitativas de Estado Ambiental propostas na metodologia de Rodriguez, Silva e Cavalcanti (2004) que define o Estado Ambiental como (a) Estável, (b) Medianamente Estável (sustentável), (c) Instável (insustentável), d) Crítico e (e) Muito Crítico.

\section{RESULTADOS E DISCUSSÕES}

Tendo em vista as características morfológicas apresentadas e a compreensão sistêmica, o Litoral Sul do Estado de São Paulo, mais especificamente os municípios de Iguape, Ilha Comprida e Cananéia, pode ser entendido como uma composição de geossistemas conectados entre si. Ocorre um permanente fluxo de matéria e energia entre eles, resultando na construção 
de seus modelados e de processos morfogenéticos atuantes. Esta interação define a dinâmica física da paisagem da área de estudo.

A partir das proposições apresentadas pela metodologia adotada nessa pesquisa (RODRIGUEZ,
SILVA e CAVALCANTI, 2004), foi possível por meio da integração dos componentes naturais, a elaboração da documentação cartográfica síntese, denominada Carta de Geossistemas (Figura 2).

Figura 2: Carta de Geossistemas do Litoral Sul do Estado de São Paulo

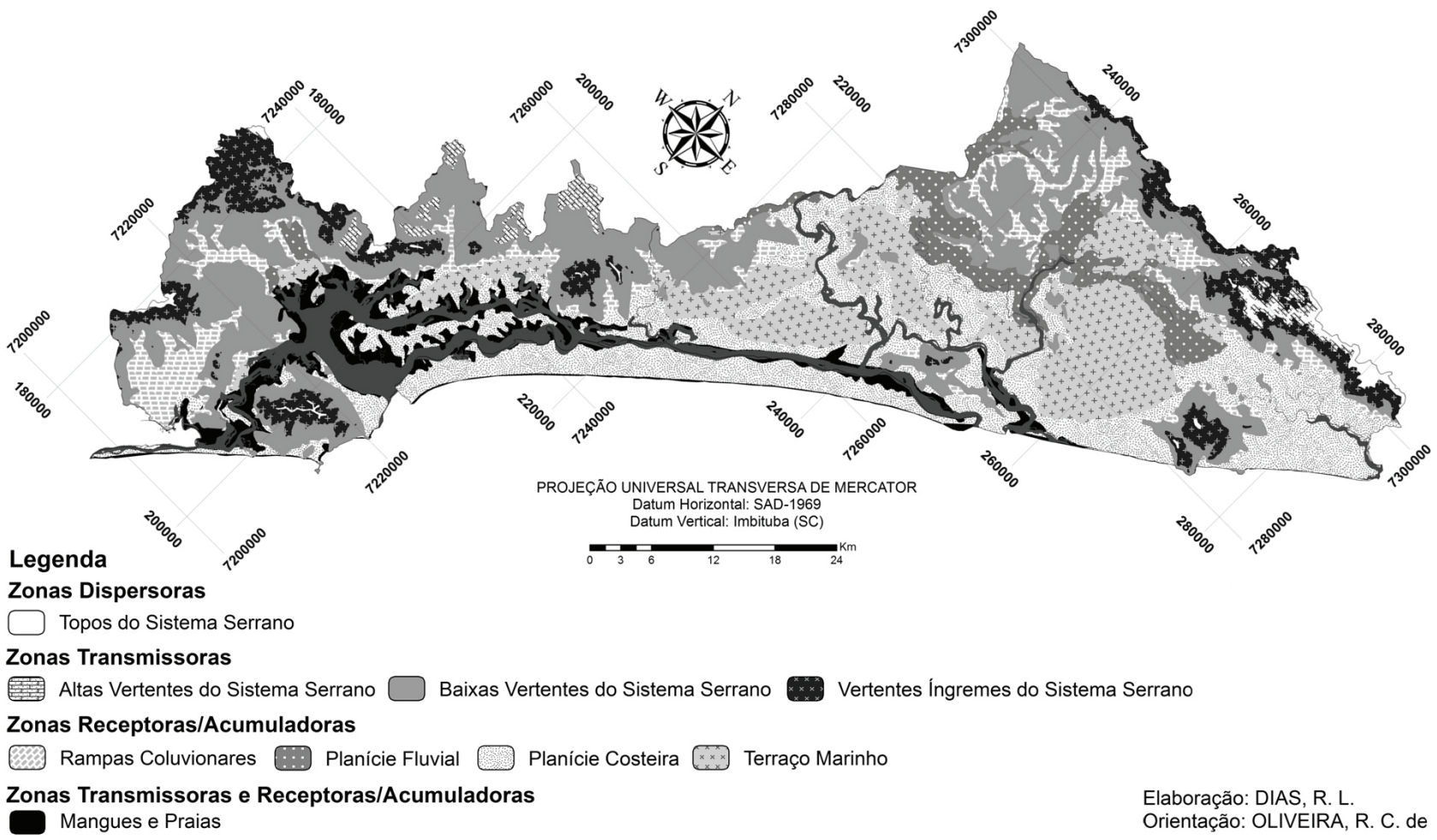

Por meio da análise dos geossistemas tais como os sistemas de tipologia de processo-resposta, verifica-se que a área de estudo apresenta quatro geossistemas, que foram compreendidos pela dinâmica de fluxo de energia e matéria, processos morfogenéticos atuantes e morfologia resultante da atuação destes processos.

A análise da documentação cartográfica e a correlação das informações levantadas permitiram a particularização de áreas que apresentavam certa homogeneidade dos aspectos físicos da paisagem. Como critério básico de definição e mapeamento dos geossistemas, foi considerado em primeiro plano a compartimentação geomorfológica, entendendo que este documento sintetiza as informações físicas da área de estudo.

O primeiro geossistema definido foi o das Zonas Dispersoras, que é composto pelos topos da região serrana e dos morros residuais. Os topos da região serrana têm como características a convexidade, com grau de declive intermediário entre 20 a $30 \%$, padrão de drenagem difuso com predominância de rios de primeira ordem. Já os topos dos morros residuais apesar de apresentarem mesma morfologia, possuem maiores índices de declividade, com predomínio de valores superiores a $30 \%$.

O geossistema das Zonas Transmissoras foi o segundo definido. Este é um sistema transicional, representado pelas escarpas da região serrana e dos morros residuais. Devido a fatores estruturais como presença de falhas, em que a drenagem se encaixa esculpindo vales em sua predominância em formato de "V", existe uma diferenciação tipológica das escarpas, as quais possuem uma variedade em sua declividade, dependendo do setor da vertente em que estão localizadas. As Altas Vertentes do Sistema Serrano estão 
localizadas logo abaixo dos Topos, com declividades predominantes superiores a $30 \%$ e com altitudes superiores a 750 metros. As Vertentes Íngremes do Sistema Serrano constituem os trechos das vertentes localizados no setor intermediário da escarpa, entre as cotas de 300 a 750 metros, e possuem declividades entre 20 a $30 \%$. Por último, as Baixas Vertentes do Sistema Serrano são as vertentes localizadas na área de contato com a planície, entre as cotas de 50 a 300 metros, com declividades intermediárias, em sua grande maioria entre 10 a $20 \%$.

A Zona Transmissora tem a função de deslocar o fluxo de matéria e energia perdida pelos geossistemas de dispersão para os de recepção. Por causa desta característica, neste sistema predominam os processos morfogenéticos em relação aos pedogenéticos, resultando em uma paisagem de escarpas íngremes, com perfis pedológicos em sua maioria de baixo desenvolvimento, sustentado basicamente pela cobertura vegetal de Floresta Ombrófila.

Na região das planícies litorâneas, representada pelas Bacias Sedimentares Cenozóicas e Formações do Quaternário Continental, existem dois geossiste- mas, que têm como características fundamentais a dissipação da energia e o acúmulo de material.

O geossistema das Zonas Receptoras/Acumuladoras é marcado pela variedade de depósitos de sedimentos marinhos, fluviais e continentais ainda inconsolidados, caracterizados pela vegetação das restingas. Este geossistema foi subdivido em rampas coluvionares, planície fluvial, planície costeira e terraço marinho.

Já o geossistema das Zonas Dispersoras e

Receptoras/Acumuladoras caracteriza-se pela atuação e influência oceânica, só que retrabalha os sedimentos depositados, modificando as características e a dinâmica da paisagem destas áreas. Este sistema é composto por praias e mangues.

A partir do exposto acima, verifica-se que a área de estudo apresenta complexa dinâmica de organização do relevo, com diferentes compartimentos geomorfológicos com características distintas, em conseqüência da variação dos componentes físicos do relevo.

Devido ao uso e ocupação das terras, foi elaborada a Carta de Sistemas Antropo-Naturais (Figura 3), que relaciona o tipo de uso e a função de cada sistema.

Figura 3: Carta de Sistemas Antropo-Naturais do Litoral Sul do Estado de São Paulo

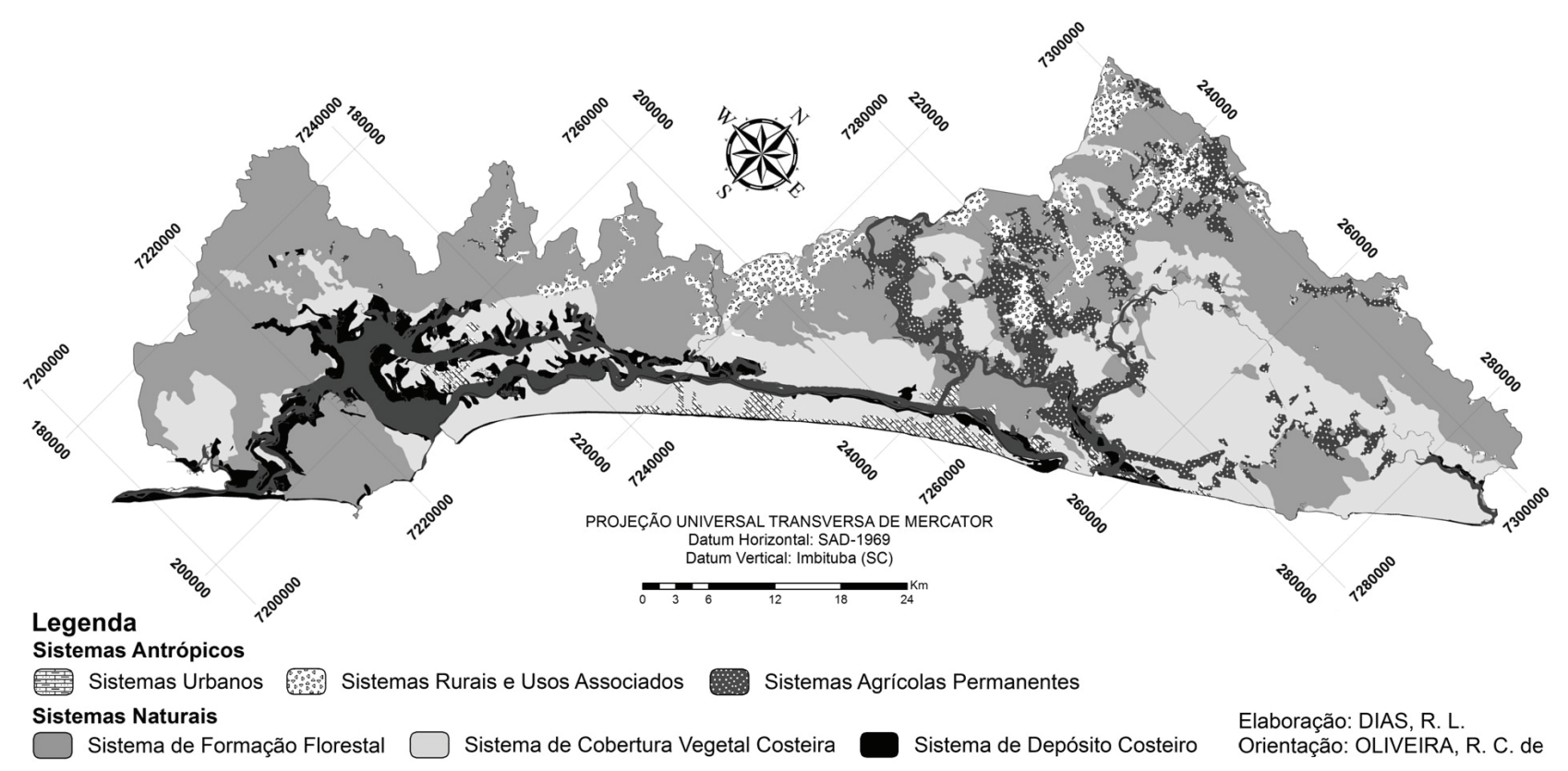

Em relação aos Sistemas Antropo-Naturais foram identificados dois sistemas: Sistemas Antrópicos e Sistemas Naturais.
Os Sistemas Antrópicos foram subdivididos em três categorias de uso de acordo com o nível de ocupação: 1) sistemas urbanos que são representados 
pelas áreas urbanas dos municípios; 2) sistemas rurais e usos associados, formados pelas propriedades rurais e seus usos; 3 ) sistemas agrícolas permanentes, compostos pelas áreas de cultivos agrícolas, principalmente a monocultura da banana.

Os Sistemas Naturais foram subdivididos a partir da cobertura vegetal natural: 1) Sistema de Formação Florestal, composto pela Floresta Ombrófila (Mata Atlântica), situada em sua quase totalidade nas áreas serranas, nas escarpas e nos sopés da serra; 2) Sistema de Cobertura Vegetal Costeira representado pelas restingas que ocupam grande parte da planície costeira; 3) Sistema de Depósito Costeiro representado pelas áreas de mangues e pelas praias.
Assim, o estudo dos geossistemas e dos sistemas antrópicos auxiliou na busca do estado ambiental, visando o entendimento dos níveis de estabilidade da área de estudo, segundo a metodologia proposta por Rodriguez, Silva e Cavalcanti (2004).

A Carta de Estado Ambiental (Figura 4), que representa os níveis de estabilidade, foi definida a partir da correlação do estado de preservação dos sistemas, perante a dinâmica de uso e ocupação das terras, que alterou as características dos processos formadores da paisagem.

Figura 4: Carta de Estado Ambiental do Litoral Sul do Estado de São Paulo

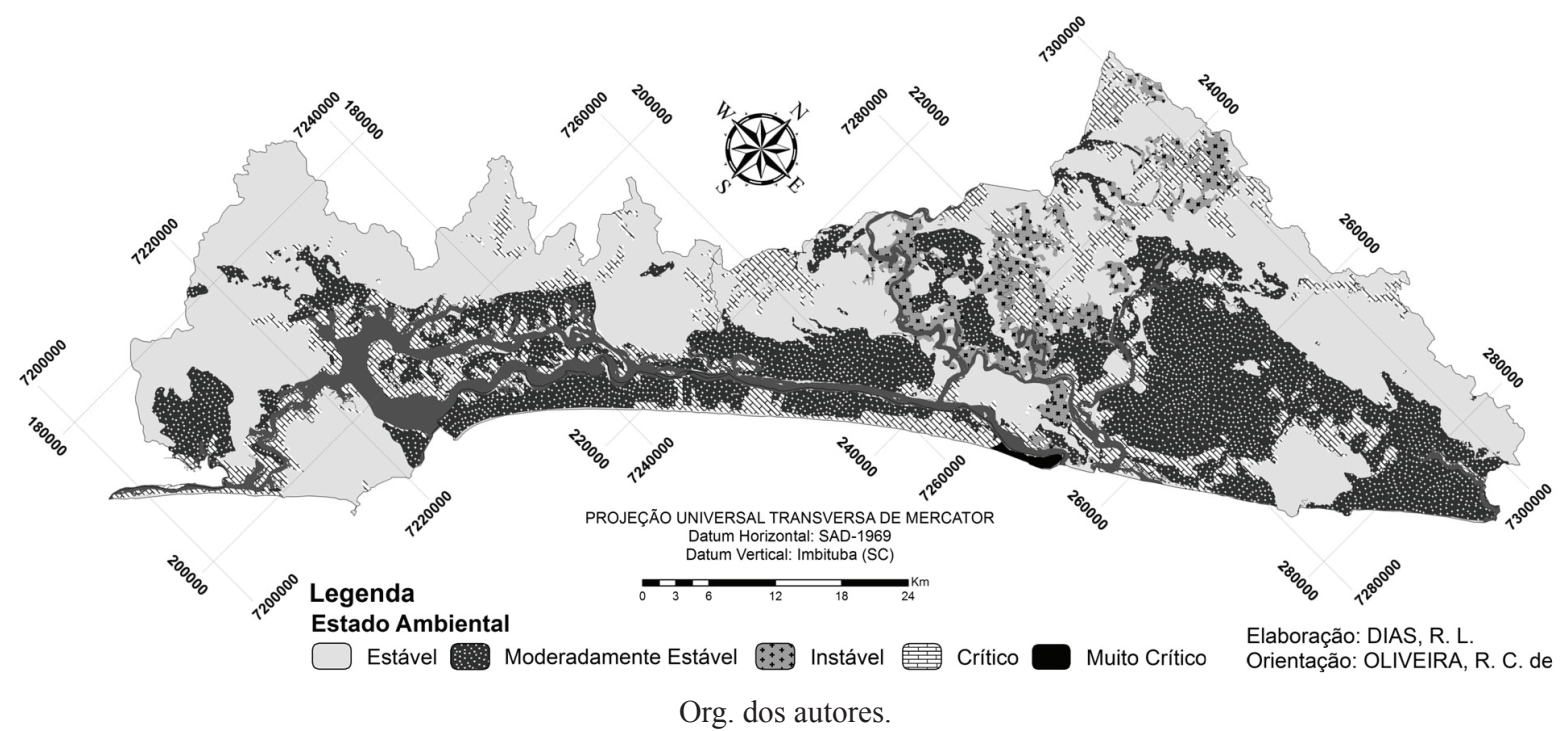

Devido às características da área de estudo, foram observadas duas dinâmicas geomorfológicas distintas. A primeira está relacionada às planícies, cujo relevo relativamente plano permitiu o desenvolvimento urbano, resultando na modificação da dinâmica natural, estabelecendo novos processos de formação da paisagem. Estas áreas foram classificadas como Críticas. A segunda se refere à região serrana de difícil acesso, que apresenta intensa atuação dos processos geomorfológicos, e encontra-se preservada, com manutenção de suas características iniciais, o que possibilita classificá-la em estado ambiental Estável.

A planície apresenta algumas áreas que mantiveram seu sistema natural com relativa preserva- ção, em locais onde não houve ocupação antrópica de fato, resultando em um grau de preservação das características intrínsecas de seus sistemas. Estas áreas, compostas principalmente pela vegetação de restinga, tiveram seu estado ambiental classificado como Moderadamente Estável, já que por se tratar de uma área de planície, o processo de ocupação torna-se mais propício, interferindo na estabilidade do sistema.

Áreas rurais e agrícolas localizadas no interior de uma Unidade de Conservação tiveram seu estado ambiental classificado como Crítico, podendo-se citar como um exemplo, as plantações de bananas existentes na APA Cananéia-Iguape-Peruíbe. Quando os geossistemas encontram-se fora dos limites das 
Unidades de Conservação, o estado ambiental destes foi classificado como Instável, já que a ocupação antrópica interferiu na dinâmica natural do sistema.

O geossistema dos Manguezais, apesar de apresentar alto grau de conservação de suas características iniciais, possui uma dinâmica de processos extremamente instável, fazendo com que esta área tenha grande potencial de fragilidade, pois depende de uma conjuntura de fatores para se manter em funcionamento. Sendo assim, o estado ambiental deste geossistema foi classificado como Crítico. Ressalta-se que nas áreas de manguezais a população local faz uso deste ambiente natural dela como prática comercial retirando do mangue a fauna local para comércio e consumo, o que provoca alteração das características naturais deste sistema.

As áreas de estado ambiental mais degradado estão relacionadas com intenso processo de uso e ocupação antrópico, que provocou grande modificação na dinâmica de funcionamento da paisagem natural, intensificando os processos geomorfológicos. Este é o caso da ponta Nordeste do município de Ilha Comprida, que devido à ocupação sem planejamento e a ausência de compreensão da dinâmica física, sofre com o processo de erosão marinha, com o mar avançando sobre as casas, destruindo-as. Sendo assim, esta área foi classificada como Muito Crítico.

Os problemas ambientais relacionados à região do Litoral Sul do Estado de São Paulo devem ser observados de acordo com as características naturais das duas unidades morfoestruturais que organizam este cenário, o Cinturão Orogênico do Atlântico e as Bacias Sedimentares Cenozóicas.

O Cinturão Orogênico do Atlântico, apesar de ser classificado como um sistema em estado ambiental Estável, devido à baixa ou inexistente interferência antrópica, apresenta diversos problemas ambientais resultantes da instabilidade natural do relevo, como por exemplo, os movimentos de massa na região serrana.

Devido à característica litológica do sistema serrano, marcada pela coesão do material, a água busca as linhas de falha e fissuras, ocorrendo o desprendimento da rocha a partir do intemperismo físico, provocando a queda de blocos. Outro fator preponderante são os altos índices pluviométricos, que saturam o solo, resultando na perda momentânea de suas características naturais, ocasionando deslizamentos.

Nas áreas agrícolas permanentes encontradas no sopé das escarpas, os processos geomorfológicos encontram-se intensificados, principalmente em conseqüência do sistema radicular das plantações de banana. Este tipo de raiz retém a água no solo, deixando-o encharcado, resultando na modificação do escoamento sub e superficial, o que intensifica os processos de deslizamento de massa.

Nas Bacias Sedimentares Cenozóicas, prevalece a acomodação de sedimentos nas zonas de planícies, tanto marinha, fluvial ou flúvio-marinha, advindos tanto das áreas de planalto e como do oceano.

Por conta da ocupação antrópica, com a conseqüente impermeabilização do solo e alteração dos canais de drenagem, a dinâmica natural das planícies foi alterada, resultando na mudança da vazão dos rios, agravando a problemática natural desta área. Enchentes e inundações ocorrem naturalmente na região das planícies em conseqüência do escoamento superficial acumulado nestas áreas, porém as modificações inseridas na paisagem pelo homem, principalmente a criação de áreas urbanas, acabam agravando estes processos.

Além disto, outro fenômeno impactante foi a construção do Valo Grande no século XIX, no município de Iguape, que até os dias atuais interfere no equilíbrio natural da paisagem, devido à alteração do processo de erosão e sedimentação, além da influência na qualidade das águas na região estuarina.

\section{CONSIDERAÇÕES FINAIS}

As características apresentadas sobre a área de estudo apontam uma paisagem com duas dinâmicas muito distintas. A primeira delas é a região serrana, caracterizada por altos índices de declividade e grandes variações altimétricas, com uma cobertura vegetal complexa, que ao mesmo tempo protege o solo e exerce, em função de seu peso e das características do solo pouco desenvolvido, pressão sobre ele, impulsionando a ocorrência de processos erosivos como movimentos de massa e quedas de bloco. A segunda é representada pelas planícies costeiras, formadas por processos ligados à deposição flúvio-marinha, constituindo-se de material inconsolidado constantemente retrabalhado pela dinâmica fluvial e pela variação das marés. Este 
setor apresenta baixos índices de declividade e altitudes inferiores a 20 metros.

Desta forma, o estudo dos atributos naturais possibilitou identificar que prevalece a morfogênese sobre pedogênese, pois no ambiente serrano o relevo é intensamente dissecado pela ação dos agentes intempéricos, enquanto na zona de planície predominam os processos deposicionais, oriundos de diferentes mecanismos (deposição fluvial, eólica e marinha).

Além disto, existe uma desproporcionalidade no uso e ocupação das terras, entre os sistemas naturais e os sistemas antrópicos.

Nas áreas em que prevalecem os sistemas naturais, a delimitação de Unidades de Conservação objetiva a sua proteção. Nas áreas ainda não protegidas por tal mecanismo legal, há uma forte tendência a transformações ambientais decorrente do crescimento populacional, da expansão urbana e do uso predatório dos recursos naturais.

No que se refere às áreas que apresentam ocupação antrópica, foi observada grande intervenção na dinâmica da paisagem. Em alguns locais, esta intervenção modificou os processos geomorfológicos, intensificando assim os processos erosivos e a degradação do meio. Assim, a partir da classificação do estado ambiental proposta por Rodriguez, Silva e Cavalcanti (2004), foi possível estabelecer o grau de instabilidade dos geossistemas.

Nesta perspectiva, a adoção da idéia de geossistema, como categoria de análise da paisagem, deve ser posta em prática, visto de forma integrada, representada por modelos que possam ser aplicados e que contribuem para a solução de problemas que afligem a humanidade, devido à forma de uso e ocupação das terras, empregado pelo homem atualmente.

Porém, de acordo com as características de uso e ocupação encontradas na área de estudo, houve dificuldade de estabelecer medidas paliativas acerca de um novo modelo de uso e ocupação das terras visando a estabilidade dos geossistemas. Isto ocorreu em razão da problemática da escala de trabalho regional, que busca identificar os comportamentos gerais da dinâmica da paisagem e do uso antrópico. No entanto, os problemas ambientais nas áreas urbanas e rurais ocorrem de forma pontual, exigindo uma escala de trabalho com maior detalhamento.

\section{REFERÊNCIAS}

ALMEIDA, F. F. M. Fundamentos Geológicos do Relevo Paulista. Boletim Geológico n. 41, São Paulo, Instituto Geográfico e Geológico, 1964.

AMORIM, R. R., OLIVEIRA, R. C. Análise geoambiental dos setores de encosta da área urbana de São Vicente-SP. Sociedade e Natureza. Ano 19, n. 37. 19-40p, 2007

BERTRAND, G. Paisagem e geografia Global. Esboço metodológico. Cadernos de Ciências da Terra, (13), p. 1-27, 1971.

DIAKONOV, K. N. Geofísica das paisagens: método dos balances. Moscou. Editora da Universidade Estadual de Moscou. 96p, 1988.

HENRIQUE, W. Zoneamento Ambiental: uma abordagem geomorfológica. Rio Claro: IGCE/UNESP Dissertação (Mestrado em Geografia), 2000.

IPT- INSTITUTO DE PESQUISAS TECNOLOGICAS. Mapa Geomorfológico do Estado de São Paulo. São Paulo. Monografias, n. 6, v. I-II, 1981.

GUERRA, A.T. Dicionário Geológico - Geomorfológico, $8^{\text {a }}$ ed. IBGE, Rio de Janeiro, 1993.

GUERRA, A. J. T.; MARÇAL, M. S. Geomorfologia Ambiental. Rio de Janeiro: Bertrand Brasil, 2006.

RODRIGUEZ, J. M. M. Análise e síntese da abordagem geográfica da pesquisa para o planejamento ambiental. Revista Departamento de Geografia da FFLCH/USP. São Paulo, v.9, 1994.

RODRIGUEZ, J. M. M., MARTINEZ, M. C. La regionalización geoecológica como base para la deternimación del estudo y La situación médio-ambiental de Cuba. La Havana: Seccíon Cubana de la U. G. I. 12p, 1998.

RODRIGUEZ, J. M. M.; SILVA, E. D.; CAVALCANTI, A. P. B. Geoecologia da paisagem: uma 
visão geossistêmica da análise ambiental. Fortaleza: EDUFC, 2004.

ROSS, J. L. S; MOROZ, I. C. Mapa geomorfológico do estado de São Paulo. FFLCH-USP/FAPESP/IPT, 1997.

SOTCHAVA, V.B. O Estudo de Geossistemas. Métodos em questão, 16. IG-USP. São Paulo, 1977, 51p.

SOTCHAVA, V.B. Por uma teoria de classificação de geossistemas de vida terrestre. Biogeografia. IG-USP.

São Paulo, 1978, 23p. 